\title{
APPLICATION OF NOVEL NATURAL MUCOADHESIVE POLYMER IN THE DEVELOPMENT OF PENTOXIFYLLINE MUCOADHESIVE TABLETS
}

\author{
GNANASEKARAN JOHN SELVARAJ, ARUL BALASUBRAMANIAN*, KOTHAI RAMALINGAM
}

Department of Pharmacy Practice, Vinayaka Mission's College of Pharmacy, Vinayaka Mission's Research Foundation (Deemed to be University), Salem 636008, Tamilnadu, India

Email: arul1971@yahoo.com

Received: 24 Jul 2019, Revised and Accepted: 02 Sep 2019

\section{ABSTRACT}

Objective: The present study was planned to develop a mucoadhesive tablet formulation of the drug pentoxifylline using natural mucoadhesive polymer from the plant Ocimum basilicum Linn.

Methods: The isolated polymer was used to formulate the mucoadhesive tablets with 3 different concentrations. The tablets were formulated by using direct compression technique and evaluated for various parameters such as thickness, friability, weight variation, hardness, mucoadhesive strength, swelling index by standard methods, and the in vitro drug release studies in USP dissolution test apparatus type-II.

Results: The swelling index was indirectly proportional to the polymer concentration and the tablets with a high concentration of polymer showed better mucoadhesive strength $(28.5532 \pm 0.4660)$. The in vitro drug release showed that the drug release was indirectly proportional to the polymer concentration. The formulation F3 showed the controlled release of drug pentoxifylline (99.84 \pm 1.86$)$ for $10 \mathrm{~h}$. The mechanism of drug release was found to be Fickian diffusion and followed the zero-order kinetics, which was proved by its highest linearity ( $\left.r^{2}\right)$ in all the formulations.

Conclusion: The tablets formulated with the isolated polymer of Ocimum basilicum Linn showed the good mucoadhesive mucoadhesive property and it controlled the release of the pentoxifylline.

Keywords: Mucoadhesion, Ocimum basilicum, Pentoxifylline

(C) 2019 The Authors. Published by Innovare Academic Sciences Pvt Ltd. This is an open access article under the CC BY license (http://creativecommons.org/licenses/by/4.0/) DOI: http://dx.doi.org/10.22159/ijap.2019v11i6.35072

\section{INTRODUCTION}

Naturally acquired mucoadhesive polymers are gaining much attention in the development of various pharmaceutical dosage forms [1]. Bioadhesion, as a state in which two materials, at least one of which being of biological nature are held together for an extended period of time by interfacial forces [2]. It is also defined as the ability of a material (synthetic or biological) to adhere to a biological tissue for an extended period of time [3, 4]. Mucoadhesion is an obverse of bioadhesion, which is aimed to target the drugs to a particular mucosal area of the body. The polymers, those are water-soluble and become adhesive during hydration were used to formulate the mucoadhesive dosage forms. The mucoadhesive dosage forms are aimed to target the drug with increased gastric residence time, sustained/controlled release, minimized the first-pass effect and reduced adverse effects $[5,6]$. The mucoadhesive polymers selected should be non-toxic, non-irritant, non-absorbable, non-covalent, biocompatible, adhesive and economic in nature [7]. Either natural (gelatin, guar gum and sodium alginate) or synthetic/semi-synthetic (Hydroxypropyl methylcellulose, Carbopol 934 and Sodium carboxy methyl cellulose), may be used alone or in a combination of two or more for the mucoadhesive drug delivery systems [8-12].

Ocimum basilicum Linn. (OBL) is an erect, almost glabrous herb, belonging to the Lamiaceae family, native to Iran, Afghanistan and India, which grows to between 30 and $90 \mathrm{~cm}$ high. The leaves are ovate, lanceolate, cucuminate, toothed or entire, glabrous on both surfaces and glandular. When mature, they reach approximately 5 $\mathrm{cm}$ in length, excluding the petiole, which is approximately $2 \mathrm{~cm}$ long. The upper surface is smooth and lustrous; on the lower surface along the midrib and the petiole short, stiff hairs occur sparingly [13]. It represents an important source of essential oil used in food, pharmaceutical, perfumery and cosmetics industries [14]. Its aromatic leaves are used in fresh or dried forms as a drug in traditional medicine and as a flavoring agent in food and confectionery products as well as beverages $[13,15]$. The seeds of OBL are high in fiber (22.6\%) and in some regions of Asia like Iran and India, basil seeds are frequently included in beverages and desserts for aesthetic purposes as well as a source of dietary fiber [16].

Bhosale et al. [17] investigated the hydrogel isolated from the seeds of OBL as a binder and proved that it has potential binding and granulating property. Khazaei et al. [18] characterized the new biodegradable edible film made from OBL seed gum and revealed that it had a good potential to be used in producing edible films for various food applications. Akbari et al. [19] used supercritical carbon dioxide phase inversion technique to dry the seed mucilage to form a nanometric structure and they found the bioadhesive property of seed mucilage was good and many active pharmaceutical compounds might be loaded to the resultant nanometric structure to enhance drug release. Naji-Tabasi et al. [20] evaluated the potential of OBL seed gum nanoparticles as an oral delivery system for glutathione, which was fabricated by ion gelling technique and calcium was used as a crosslinking agent. A novel drug delivery system, loaded the drug cephalexin on the OBL seed mucilage coated magnetic nanoparticles was prepared and characterized by Rayegan et al. [21].

Even though several advances and researches have been made in the area of mucoadhesion and polymers, still the search for newer mucoadhesives are going on. Plant-derived polymers like mucilage are widely used in the pharmaceutical industry due to their emollient, lack of toxicity, and low cost. So, in this present work, an attempt was made to study the application of novel natural mucoadhesive polymer from the plant Ocimum basilicum (MAPOB) in the development of pentoxifylline mucoadhesive tablets concern to the in vitro drug release rate.

\section{MATERIALS AND METHODS}

\section{Materials}

The seeds of Ocimum basilicum were purchased from the local vendors of Chennai, Tamilnadu in the month of February 2018. The collected seeds were identified and authenticated by a botanist Dr. S. Balasubramanian, ABS Medicinal garden, Salem. The voucher specimen (OBG-1) was kept in our museum for future reference. Pentoxifylline 
was obtained as a gift sample from Shasun Pharmaceuticals, Puducherry. Microcrystalline cellulose and magnesium stearate were purchased from Central Drug House (India). Acetone, diethyl ether and petroleum ether were from Qualigens (India) and sodium hydroxide from E-Merck (India). All the chemicals used were of analytical grade.

\section{Methods}

\section{Isolation of MAPOB}

Three batches of MAPOB was prepared on a laboratory scale by the method of Rao et al. [22]. $200 \mathrm{ml}$ of cold distilled water was added to $20 \mathrm{~g}$ of the seed powder and the slurry was prepared. Then the slurry was added to $800 \mathrm{ml}$ of boiling water and boiled for another $20 \mathrm{~min}$ with continuous stirring. The solution was kept overnight to settle the solid matter. The clear solution was centrifuged for $20 \mathrm{~min}$ at 5000 rpm. The supernatant fluid was separated and twice the volume of acetone was added with continuous stirring. The formed precipitates were filtered and washed with petroleum ether and diethyl ether and then dried under vacuum at $50-60^{\circ} \mathrm{C}$. The dried materials were sieved through sieve No 80 and used for the formulation of tablets.

\section{Formulation of mucoadhesive tablets}

The mucoadhesive tablets of pentoxifylline (MATP) were prepared by using direct compression technique. Pentoxifylline, mucoadhesive polymer, microcrystalline cellulose, magnesium stearate were accurately weighed, mixed uniformly and this mixture was compressed into tablets by using Elite multi-station punching machine (Erweka) with $10 \mathrm{~mm}$ flat punches. The compression force was adjusted to give tablet hardness in the range of 7 to $11 \mathrm{kp}$. The constituent of the formulation is presented in table 1 .

Table 1: Formulation of mucoadhesive tablets of pentoxifylline

\begin{tabular}{llll}
\hline Ingredients & F1 & F2 & 400 \\
Pentoxifylline & 400 & 400 & 122 \\
Microcrystalline cellulose & 152 & 60 \\
MAPOB & 30 & 92 \\
Magnesium stearate & 18 & 18 \\
Total weight (mg) & 600 & 600 & 600 \\
\hline
\end{tabular}

All the quantities are in $\mathrm{mg}$

\section{Swelling study}

The formulated MATP's were weighed (W1) individually and incubated at $37 \pm 0.5{ }^{\circ} \mathrm{C}$ separately in an agar gel $(2 \%)$ plates The tablets were removed from petri dish at regular time intervals of $1 \mathrm{~h}$ up to $6 \mathrm{~h}$ and the excess water on the surface was removed carefully with filter paper. The swollen tablet was reweighed (W2) and the swelling index was calculated by using the formula [23-25].

$$
\text { Swelling index }=\frac{\mathrm{W} 2-\mathrm{W} 1}{\mathrm{~W} 1}
$$

\section{Mucoadhesive strength}

The mucoadhesive strength (MS) of the formulated MATP's was measured by using a modified 2 -arm balance (fig. 1) with rabbit buccal mucosa [26]. The apparatus consists of a modified double beam physical balance in which the right pan has been replaced by a glass slide with copper wire and additional weight, to make the right side weight equal with left side pan. A Teflon block of $3.8 \mathrm{~cm}$ diameter and $2 \mathrm{~cm}$ height was fabricated with an upward protrusion of $2 \mathrm{~cm}$ height and $1.5 \mathrm{~cm}$ diameter on one side. This was kept in a beaker filled with phosphate buffer (PB) $\mathrm{pH}$ 6.8, which was then placed below the right side of the balance.

The rabbit buccal mucosa was used as the membrane and $\mathrm{PB} \mathrm{pH}$ 6.8 as moisturizing liquid. The rabbit buccal mucosa was obtained from the local slaughterhouse and stored in Krebs buffer at $4{ }^{\circ} \mathrm{C}$ upon collection. The experiment was conducted within $3 \mathrm{~h}$ of the procurement of rabbit mucosa. The mucous layer was separated by using a surgical blade and washed with $\mathrm{PB} \mathrm{pH}$ 6.8. It was then tied over the protrusion in the Teflon block using a thread. This set was kept in a glass beaker, which was filled with PB pH 6.8 up to the surface of the buccal mucosa to maintain buccal mucosa viability.

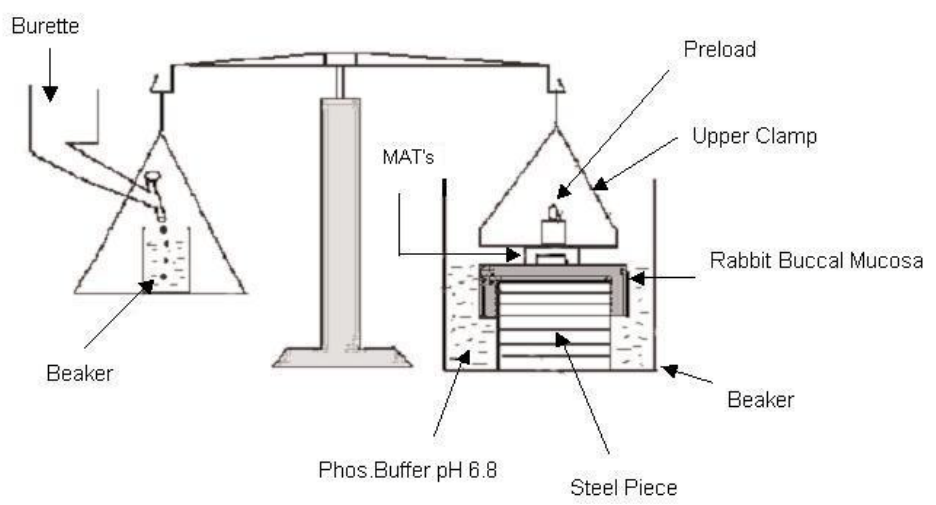

Fig. 1: Mucoadhesive strength measurement apparatus

The MATP was attached to the upper clamp of the apparatus and then the beaker was raised slowly until contact between rabbit buccal mucosa and MATP was established. A weight of $100 \mathrm{~g}$ was kept on the clamp for a pre-load time of 5 min to create a strong adhesion between rabbit buccal mucosa and the MATP. The pre-load and pre-load time were kept as constant for all the MATP's. After the pre-load time, the weight was removed from the clamp, and water was added at a rate of $60 \mathrm{drops} / \mathrm{min}$ into the beaker until the separation of rabbit buccal mucosa and MATP. The weight of water required to detach the MATP from buccal mucosa was noted as MS and the same was repeated with fresh mucosa $(n=6)$. The MS was used to calculate the force of adhesion [25, 27-29] using formula.

$$
\text { Force of adhesion }(\mathrm{N})=\frac{\mathrm{MS}}{100} \times 9.81
$$




\section{In vitro drug release studies}

The in vitro dissolution studies were carried out in Type-II USP dissolution test apparatus, using $900 \mathrm{ml}$ of phosphate buffer saline (PBS) $\mathrm{pH}$ 6.8. The dissolution test was carried out at a speed of 50 rpm and the temperature was maintained at $37^{\circ} \mathrm{C} \pm 0.5^{\circ} \mathrm{C}$. $5 \mathrm{ml}$ of the sample was withdrawn periodically at predetermined time intervals and assayed spectrophotometrically at $274 \mathrm{~nm}$ using Shimadzu UV spectrophotometer 1601. All the experiments were done thrice and the standard curve specification was $\mathrm{y}=0.0392 \mathrm{X}\left(r^{2}\right.$ $=0.9993, \mathrm{n}=10$ ).

\section{Drug release kinetics}

The data obtained from in vitro release of drug was plotted in various kinetic models such as zero-order (cumulative amount of drug released vs time), first-order (log cumulative percentage of drug remaining vs time), and Higuchi's model (cumulative percentage of drug released vs square root of time) to know the release kinetics [30-32].

\section{Mechanism of drug release}

The mechanism of drug release of the prepared MATP was calculated by using Korsmeyer equation (log cumulative percentage of drug released vs log time), and the exponent $n$ was calculated through the slope of the straight line [33].

\section{Statistical analysis}

Each experiment was repeated at least three times. The results are expressed as mean $\pm \mathrm{SD}$. One-way analysis of variance was used to test the statistical significance of differences among groups. Statistical significance of the differences of the means was determined by Student's t-test.

\section{RESULTS AND DISCUSSION}

Polymers are most commonly used as an adjuvant in the manufacturing of different pharmaceutical dosage forms. They possess a variety of pharmaceutical properties, which include binding, disintegrating, suspending, emulsifying and sustaining properties at different proportion in different pharmaceutical dosage forms [34, 35]. But in the view of biodegradation and biocompatibility, the natural polymers are preferred. Even though many polymers are available, a search for new polymers still interesting to get more efficacious polymers with less toxic. The purpose of this research is to give scientific validation to the plant by isolating polysaccharides and then to screen them for the potential mucoadhesive property. The current research work is focused on the identification of a new mucoadhesive polymer and its application on the development of pentoxifylline mucoadhesive tablets

The plant OBL was selected for this study and the mucilage was isolated from the seeds by the method of Rao et al., [22]. Three different concentrations of MAPOB was used to formulate mucoadhesive tablets of pentoxifylline. The formulated tablets showed a satisfactory evaluation report on hardness, friability, weight variation and drug content. The results were shown in table 2. The increase in concentration $[25,36]$ of the mucoadhesive polymer, increased the tablet hardness.

Table 2: Results of evaluation of thickness, hardness, friability weight variation and drug content for mucoadhesive formulations

\begin{tabular}{llllll}
\hline Formulation code & $\begin{array}{l}\text { Thickness } \\
(\mathbf{m m} \pm \text { SD) }\end{array}$ & $\begin{array}{l}\text { Hardness } \\
\text { (Neutons } \pm \text { SD }\end{array}$ & $\begin{array}{l}\text { Friability } \\
\text { (\% } \pm \text { SD) }\end{array}$ & Weight variation (mg $\pm \%)$ & $\begin{array}{l}\text { Drug content } \\
\text { (\% } \pm \text { SD) }\end{array}$ \\
\hline F1 & $6.259 \pm 0.022$ & $68.649 \pm 4.004$ & $0.2394 \pm 0.0895$ & $0.6004 \pm 1.81$ & $100.11 \pm 4.57$ \\
F2 & $6.266 \pm 0.024$ & $73.553 \pm 4.623$ & $0.2391 \pm 0.0194$ & $0.5990 \pm 1.79$ & $99.08 \pm 4.33$ \\
F3 & $6.249 \pm 0.029$ & $79.4367 \pm 5.064$ & $0.2053 \pm 0.1018$ & $0.5992 \pm 2.16$ & $100.78 \pm 2.48$ \\
\hline
\end{tabular}

(All values are mean $\pm \mathrm{SD} ; \mathrm{n}=6$ )

An appropriate swelling index is mandatory for the uniform and sustained release of the drug and effective mucoadhesion $[25,36]$. The results of the swelling study showed that the rate of swelling was indirectly proportional to the concentration of MAPOB in tablets. The tablets formulated (F1) with a lower concentration of MAPOB showed a high swelling index (5.038 \pm 0.182$)$, and the formulation (F3) with a higher concentration of MAPOB showed lower swelling index (3.334 \pm 0.087 ). Formulations F2 and F3 were showed no significant change in the shape and form of tablets for a period of up to $6 \mathrm{~h}$, when they kept in the agar gel (2\%) plate, but the formulation F1 changed the shape and form completely. The results of the swelling index have been tabulated in table 3 . The tablets, which had high swelling index described that the formation of a gel by the hydration of the polymer, did not have good adhesion, probably due to overhydration resulting less MS. The formulation F3 tablets adhered well to the agar gel plates and a layer of gel was seen adhering to the sides of the tablets. This suggests that the gel formed was firm and there was no overhydration, making the tablets adhere well to the plates.

Table 3: Results of swelling index, mucoadhesive strength and force of adhesion

\begin{tabular}{lllll}
\hline S. No. & Formulation & Swelling index ( \pm SD) & Mucoadhesive strength (g士SD) & Force of adhesion (Newton \pm SD) \\
\hline 1 & F1 & $5.038 \pm 0.182$ & $9.3566 \pm 0.0866$ & $0.9179 \pm 0.0085$ \\
2 & F2 & $4.471 \pm 0.120$ & $19.7506 \pm 0.5695$ & $1.9375 \pm 0.0599$ \\
3 & F3 & $3.334 \pm 0.087$ & $28.5532 \pm 0.4660$ & $2.8011 \pm 0.0457$ \\
\hline
\end{tabular}

(All values are mean $\pm S D ; n=6$ )

MS of MATOB with rabbit buccal mucosa is shown in table 3 . Wetting, interpenetration, and mechanical interlocking between mucus and polymer were the three different stages of occurrence of the mucoadhesion. The MS is affected by various factors such as polymer's swelling rate, molecular weight [37], contact time with mucus, and the biological membrane used for the study [38]. Tablets formulated with a high concentration of MAPOB showed good MS in a contact time of $5 \mathrm{~min}$. This high MS of MAPOB may be due to the formation of secondary bioadhesion bonds with mucin and interpenetration of the polymer chains in the interfacial region. However, the formulations F1, F2 and F3 exhibited MS of
$9.3566 \pm 0.0866, \quad 19.7506 \pm 0.5695$ and $28.5532 \pm 0.4660 \quad \mathrm{~g}$ respectively, with rabbit buccal mucosa.

The in vitro drug release studies (fig. 2) were carried out and the results showed that the release of the drug from the formulated tablets were based on the MAPOB concentration. The formulation F1, which has a high swelling index, becomes gel-like due to the over hydration of polymer, leads to more \% of drug diffused from the polymer matrix [39]. The $\%$ of drug release $(99.03 \pm 2.58)$ was more in formulation F1 but it was within a period of $4 \mathrm{~h}$. The \% of drug release was decreased gradually to $99.96 \pm 2.31$ at $8 \mathrm{~h}$ for the formulation F2 and $99.84 \pm 1.86$ at $10 \mathrm{~h}$ for the formulation F3. This 
extend of time-release may be due to the increase in the concentration of MAPOB. It may be due to the in situ gelling property of mucoadhesive polymer, which slows the dissolution.
Tablets of batch F3 was remaining intact during the entire $10 \mathrm{~h}$ study period and the batch F1 and F2 were up to $4 \mathrm{~h}$ and $8 \mathrm{~h}$ respectively.

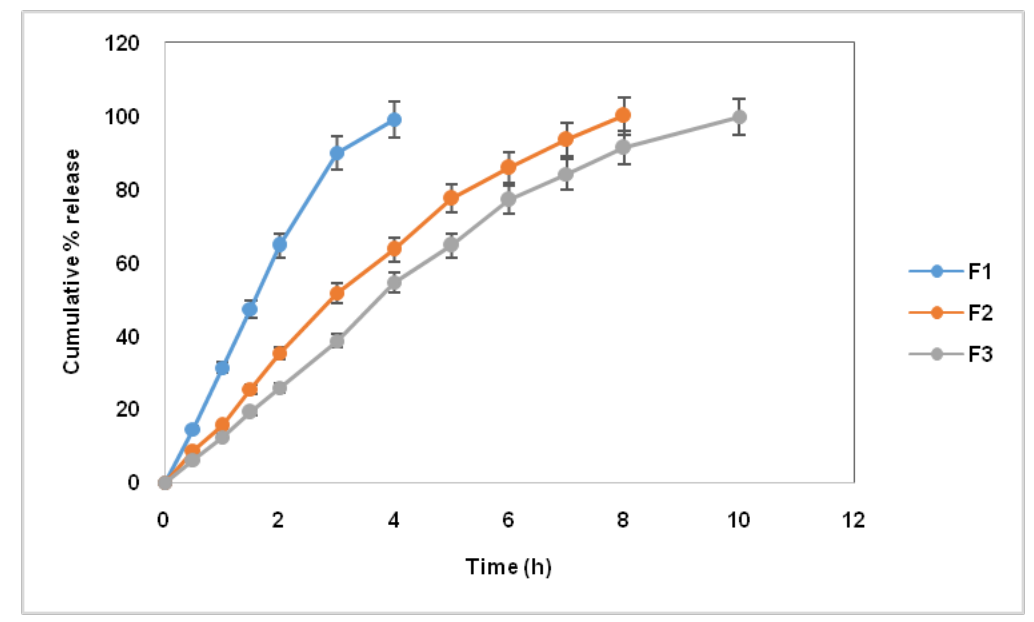

Fig. 2: The cumulative release profile of mucoadhesive tablets of pentoxifylline formulated with MAPOB. $(\operatorname{mean} \pm S D ; n=3)$

The zero-order release described that the release rate is doseindependent, which shows the cumulative amount of drug release vs time for zero-order kinetics. The first order release described the release rate is dose-dependent, which shows the log cumulative percent drug remaining vs time [40]. Higuchi's model described the release of drugs from an insoluble matrix as a square root of a timedependent process based on Fickian diffusion. Higuchi square root kinetics, showing the cumulative percent drug release vs the square root of time [41]. The release constant was calculated from the slope of the appropriate plots, and the regression coefficient $\left(r^{2}\right)$ was determined (table 3). It was found that the in vitro drug release of mucoadhesive tablets of pentoxifylline was following zero-order release, as the plot showed the highest linearity $\left(r^{2}=0.9693,0.9761\right.$ and 0.9731 ) for the formulations, F1, F2 and F3 respectively), and Higuchi's $\left(r^{2}=0.9887,0.9953\right.$ and 0.9896), which indicates the release rate was not depending upon the dose of the drug.

Table 3: Release kinetics of mucoadhesive tablets of pentoxifylline

\begin{tabular}{|c|c|c|c|c|c|c|c|c|}
\hline \multirow[t]{2}{*}{ Formulation } & \multicolumn{2}{|c|}{ First order } & \multicolumn{2}{|c|}{ Zero-order } & \multicolumn{2}{|l|}{ Higuchi } & \multicolumn{2}{|c|}{ Korsmeyer Peppas } \\
\hline & Slope & $r^{2}$ & Slope & $r^{2}$ & Slope & $r^{2}$ & Slope & $r^{2}$ \\
\hline F1 & 0.543 & 0.9197 & 25.999 & 0.9693 & 69.229 & 0.9887 & 0.8502 & 0.9772 \\
\hline $\mathrm{F} 2$ & 0.1675 & 0.9614 & 12.892 & 0.9761 & 45.795 & 0.9953 & 0.8807 & 0.9842 \\
\hline F3 & 0.1313 & 0.9626 & 10.805 & 0.9731 & 41.794 & 0.9896 & 0.9357 & 0.9892 \\
\hline
\end{tabular}

The corresponding Korsmeyer-Peppas [39] plot (log cumulative percent drug release vs time) indicated good linearity $\left(r^{2}=0.9772,0.9842\right.$ and 0.9892) and showed the matrix release of the drug pentoxifylline.

\section{CONCLUSION}

The polymers are playing an important role in the field of controlled or sustained release drug delivery system. Since the seeds of the plant, OBL has rich mucilage content and that may prove to be an alternative to existing mucoadhesive polymers. Therefore, in the present study, an attempt was made to study the application of a novel mucoadhesive polymer isolated from the plant OBL for the development of pentoxifylline mucoadhesive tablets. The patient compliance may be increased, when the dosing frequency of the drug reduced. The tablets formulated with MAPOB showed the controlled release of pentoxifylline for a period of $10 \mathrm{~h}$. The in vitro dissolution studies indicated that the drug pentoxifylline was released in zero-order pattern, as the plot showed the highest linearity. It also indicates that the increasing concentration of the polymer leads to a decrease in the release rate and increasing the mucoadhesive strength of the tablet.

\section{AUTHORS CONTRIBUTIONS}

All authors have contributed equally

\section{CONFLICTS OF INTERESTS}

All authors have none to declare

\section{REFERENCES}

1. Jimenez Castellanos MR Zia H, Rhodes CT. Mucoadhesive drug delivery systems. Drug Dev Ind Pharm 1993;19:143-94.

2. Good RJ. Definition on adhesion. J Adhes 1976;8:1-9.

3. Peppas NA, Buri PA. Surface, interfacial and molecular aspects of polymer bioadhesion on soft tissues. J Controlled Release 1985;2:257-75.

4. Longer M, Robinson J. Fundamental aspects of bioadhesion. Pharm Int 1986; 7:114-7.

5. Ahuja A, Khar RK Ali J. Mucoadhesive drug delivery systems. Drug Dev Ind Pharm 1997;23:489-515.

6. Nagai T, Machida Y. Advances in drug delivery, mucosal adhesive dosage forms. Pharm Int 1985;6:196-200.

7. Gayot A. Bioadhesive polymers. J Pharm Belg 1985;40:332-8.

8. Cilurzo F, Minghetti P, Selmin F, Casiraghi A, Montanari L. Polymethacrylate salts as new low-swellable mucoadhesive materials. J Controlled Release 2000;88:43-53.

9. Miyazaki S, Kawasaki N, Nakamura T, Iwatsu M, Hayashi T, Hou $\mathrm{WM}$, et al. Oral mucosal bioadhesive tablets of pectin and HPMC: in vitro and in vivo evaluation. Int J Pharm 2000;204:127-32.

10. Han Gon C, Jac Hee J, Chul Soon Y, Chong Dal R, Mi Kyung L, Jeong Hee $\mathrm{H}$, et al. Formulation and in vitro evaluation of 
omeperazole buccal adhesive tablet. J Controlled Release 2000;68:405-12.

11. Sang Chl S, J YK. Enhanced permeation of triamcinolone acetonide through the buccal mucosa. Eur J Pharm Biopharm 2000;40:217-20.

12. Shah HP, Prajapati ST, Patel C. Gastroretentive drug delivery systems: from conception to commercial success. J Crit Rev 2017;4:10-21.

13. Prakash V. Leafy spices. CRC Press; 1990. p. 114.

14. Simon J, Quinn J, Murray R. Basil: a source of essential oil. In: Advances in new crops. J Janick, Simon J. editors. Timloer Press, Portland, OR; 1990. p. 484-9.

15. Marotti M, Piccaglia R, Giovanelli E. Differences in essential oil composition of basil (Ocimum basilicum L.) Italian cultivars related to morphological characteristics. J Agric Food Chemo 1996;44:3926-9.

16. Mathews S. Ocimum basilicum: a new non-conventional source of fibre. Food Chem 1993;47:399-401.

17. Bhosale A, Hardikar S, Pathak A, Sable R. Investigation of hydrogel isolated from seeds of Ocimum basilicum as binder. Indian J Pharm Sci 2009;71:320-2.

18. Khazaei N, Esmaiili M, Djomeh Z, Ghasemlou M, Jouki M. Characterization of new biodegradable edible film made from basil seed (Ocimum basilicum L.) gum. Carbohydr Polym 2014;102:199-206

19. Akbari I, Ghoreishi S, Habibi N. Supercritical CO2 generation of nanometric structure from Ocimum basilicum mucilage prepared for pharmaceutical applications. AAPS PharmSciTech 2015;16:428-34.

20. Naji Tabasi S, Razavi S, Mehditabar H. Fabrication of basil seed gum nanoparticles as a novel oral delivery system of glutathione. Carbohydr Polym 2017;157:1703-13.

21. Rayegan A, Allafchian A, Sarsari IA, Kameli P. Synthesis and characterization of basil seed mucilage coated $\mathrm{Fe}_{3} \mathrm{O}_{4}$ magnetic nanoparticles as a drug carrier for the controlled delivery of cephalexin. Int J Biol Macromol 2018;113:317-28.

22. Rao PS, Srivastava HC. Tamarind. In: Industrial Gums. $2^{\text {nd }}$ edn. RL W. editor. Academic Press: New York; 1973. p. 369-411.

23. Parodi B, Russo E, Caviglioli G, Cafaggi S, Bignardi G. Development and characterization of a buccoadhesive dosage form of oxycodone hydrochloride. Drug Dev Ind Pharm 1996;22:445-50.

24. Kshirsagar R, Vikas J, Wattamwar S. Effect of different viscosity grade HPMC polymers on gastro retentive drug delivery of metformin Hcl. Int J Appl Pharm 2009;1:44-50.
25. Gnanasekaran J, Arul B, Kothai R. Development of mucoadhesive tablet of pentoxifylline using a natural polymer from Manilkara zapota linn. Int J Appl Pharm 2019;11:88-91.

26. Kashappa Goud, Desai H, Pramod Kumar TM. Preparation and evaluation of a novel buccal adhesive system. AAPS PharmSciTech 2004:5:35-8.

27. Bagul U, Gujar K, Dhat S, Aphale S, Bhavsar M. In vitro study of mucoadhesive strength of polymers for mucoadhesive drug delivery systems. Int J Curr Pharm Res 2009;1:42-6.

28. Patil P, Kulkarni SV, Rao BS, Ammanage A, Surpur C. Formulation and in vitro evaluation of mucoadhesive tablets of ofloxacin using natural gums. Int J Curr Pharm Res 2011;3:93-8.

29. Gupta S, Dev A. Formulation and characterization of mucoadhesive matrix tablet of nizatidine. Asian J Pharm Clin Res 2018;11:277-83.

30. Hadjiioannou TP, Christian GD, Koupparis MA. Quantitative calculations in pharmaceutical practices and research. New Delhi: NY-VCH publishers Inc; 1993. p. 345-8.

31. Higuchi T. Mechanism of sustained action of medication. Theoretical analysis of rate of release of solid drugs dispersed in solid matrices. J Pharm Sci 1963;52:1145-9.

32. Bourne DW. Pharmacokinetics. In: Modern Pharmaceutical. $4^{\text {th }}$ ed. Banker GS, Rhodes CT E. editor. New York: Marcel. Dekker Inc.; 2002. p. 67-92.

33. Korsmeyer RW, Gurny R, Doelker E, Buri P, Peppas NA. Mechanisms of solute release from porous hydrophilic polymers. Int J Pharm 1983;15:25-36.

34. Mithal B, Kasid J. Evaluation of suspending properties of Plantago ovata (Ispaghula) seed husk. Indian J Pharm Sci 1965;27:331-5

35. Baveja S, Gupta B. Rheology of aqueous dispersions of Plantago ovata seed husk-I. Indian J Pharm Sci 1968;30:187-94.

36. Ilango R, Kavimani S, Mullaicharam AR JB. In vitro studies on buccal strips of glibenclamide using chitosan. Indian J Pharm Sci 1997;59:232-5.

37. Saraswathi B, Balaji A, Umashankar M. Polymers in mucoadhesive drug delivery system-latest updates. Int J Pharm Pharm Sci 2013;5:423-30.

38. Park H, Robinson JR. Mechanisms of mucoadhesion of poly (acrylic acid) hydrogels. Pharm Res 1987;4:457-64.

39. Peppas NA. Analysis of fickian and non-fickian drug release from polymers. Pharm Acta Helv 1985;60:110-1.

40. Kumar BP, Kavitha P, Devi KJ. Formulation design and evaluation of mucoadhesive buccal tablets of nitroglycerin. Int J Pharm Pharm Sci 2014;6:251-9.

41. Sood A, Panchagnula R. Drug release evaluation of diltiazem cr preparations. Int J Pharm 1998;175:95-107. 